\section{Preparation of Nano Triblock Co-polymer for Desferoxiamine Delivery and Cross-Linked Copolymer for Iron Overload Disease}

\section{Athir M Haddad, Iqbal J Al-Asadi and Isra'a Q Falih}

Dept. of Chemistry, College of science,
University of Basrah, Iraq

\section{Abstract}

Some IPNs and copolymer were prepared at different ratios from bisacryl amide as crosslinking agent by Redox polymerization. These IPNs (polyacrylamideoly ethylene imine); (polyacrylamide-poly electrolyte) and poly (acrylamideacrylic acid) copolymer are examined by UV-VIS spectrophotometry method to determine their ability for linking with iron ions that are prepared with standard solution employed for this purpose. The results, indicate that the copolymer prepared from (AcAm:AcAc) with $20 \%$ (wt/wt) from bisacrylamide has the ability of removing the iron ions from the solution. The swelling ratio for the prepared IPNs and copolymers was studied as a function of time at different $\mathrm{pH}$ $(1.2,8.4)$ and distilled water; the obtained data show that the swelling ratio was increased with increasing the $\mathrm{pH}$. The morphology of copolymers was performed by scanning electron microscopy (SEM) to show the pore size. A new triblock copolymer of (Polylactide-Pluronic 127-Polylactide) is synthesized by ring opening polymerization using (DUB) Diazabicyclo-[5.4.0]-udec-7-ene as a catalyst. The triblock copolymer is characterized ${ }^{1} \mathrm{HNMR}$. Semi IPNs from triblock copolymer with acrylamide was prepared to use as a polymer drug delivery with Desferriox aminemethanesulphate (Iron overload chelating drug). The SEM for this semi IPN shows the nano structure due to the regular orientation of lactide fibers. Desferoxiamine release study as a function of time at $\mathrm{pH} 1.2$ and 8.4 for 24 hours with semi IPNs coated with tetramethylourea and without coating was also carried out. The releasing studies show that the rate of releasing at GIF is larger than SGF.

Keywords: Nano block copolymer; Desferoxiamine; Drug delivery
Corresponding author: Athir M Haddad

athirhaddad@yahoo.com

Department of Chemistry, College of science, University of Basrah, Garmat Ali, Basrah, Iraq.

Tel: $+964-7801012592$

Citation: Haddad AM, Al-Asadi IJ, Falih IQ. Preparation of Nano Triblock Co-polymer for Desferoxiamine Delivery and Cross-Linked Copolymer for Iron Overload Disease. Polym Sci. 2017, 3:1.

Received: May 05, 2017; Accepted: May 25, 2017; Published: June 05, 2017

\section{Introduction}

Hydrogels show reversible volume phase transitions depending on external stimuli factors such as temperature, solvent composition, ionic strength, $\mathrm{pH}$, electric field, light, etc. These properties make them promising materials in different fields including biotechnology, pharmaceutical, agriculture and industrial applications [1]. The possible applications include metal extraction, wastewater treatment, soft contact lenses, controlled release of drugs, enzyme supports; wound dressing, water managing materials, diapers and agrochemical release. Hydrogels are cross-linked networks of polymers, semi or fully interpenetrating networks of polymers; inter polymer complexes, and core-shell microspheres [2]. In recent years, most studies focus on the synthesis and characterization of synthetic poly hydrogels [3].
Poly hydrogels are defined as cross linked macromolecular networks. The synthetic poly gels have a resemblance to proteins prompted them to use in the modeling of biological processes. In hydrogels, apart from the hydrogen bonding $s$ and hydrophobic interactions, the coulombic attraction between oppositely charged monomer units, play a crucial role to determine their phase transitions that leads to a different chain configuration within the network structures.(Ogawa et al. [4]) design a bio chemo mechanical poly hydrogel system consisting of NIPAM, acrylic acid ( $A c A c)$, and 1-vinylimidazole (VIM) units that undergo swelling and shrinking changes due to the electrostatic interaction between the opposite charges in the network. (Takeoka et al. [5]) describe that poly hydrogels undergo a discontinuous phase transition depending on the interactions between its repeating units in the gels [6]. 
The inability to enough represses iron absorption in response to increased iron stores results in a situation in which the amount of iron in the plasma exceeds the binding capacity of transferrin. This state is known as iron overload. Its original cause can be excessive iron intake, a genetic defect or repeated blood transfusions. This production of free radicals can result in severe damage to tissue and organs and can be fatal if left untreated [7]. Iron chelation therapy acts to prevent oxidative effects by removing catalytically active iron. An excess of iron is toxic. This is due to the deleterious effects of reactive oxygen species (ROS), such as the hydroxyl radical $(\cdot \mathrm{OH})$, which is produced via the Fenton reaction.

The highly reactive $(\mathrm{OH})$ radical is able to induce cell death, initiating a series of chemical reactions with many significant biomolecules, resulting in DNA oxidation, mitochondrial damage and the peroxidation of membrane lipid $[7,8]$. In addition, excess free iron can also react with unsaturated lipids to produce alkoxyl and peroxyl radicals [9]. These oxidative reactions results in the impairment of cellular functions and lead to damage of cells, tissues, and organs which is evident in the iron loading diseases [10-12].

Iron chelation therapy involved the use of ligating drugs that avidly bind iron for the treatment of potentially fatal conditions namely iron overload and cancer [13]. By coordinating with intraand extra-cellular iron, these ligands promote the excretion and subsequent depletion of iron in biological systems. These ironchelating agents consist of a range of bidentate, tridentate, and hexadentate ligands in which two, three, or six atoms, respectively, are able to coordinate with iron, forming octahedral complexes $[13,14]$. Oxygen and nitrogen donor atoms within ligands are able to bind tightly with iron and this is illustrated within porphyin ring of heme-containing proteins where Fe- $\mathrm{N}$ bonds tie the iron center in place. As iron exists in the environment in an insoluble form, microbes have overcome this problem by excreting low molecular weight ligands, known as siderophores to specifically sequester iron in a usable form [7].

Desferal (desferrioxamine mesylate), DFO was introduced to the market for the treatment of iron Overload It is produced by fermentation of Streptomyces pilosus $[15,16]$. It is administered in a typical dose of $50 \mathrm{mg} / \mathrm{kg} /$ day as a $10 \%$ solution in sterile water ( 0.50 or $2.0 \mathrm{~g}$ vials) by subcutaneous injection. Furthermore, desferrioxamine has a short half-life of 5-10 $\mathrm{min}[17,18]$, and to improve its efficacy, the required dose is injected over a 4-12 $\mathrm{h}$ period using a small portable peristaltic pump. Accordingly, patient compliance is very low, especially among children due to the pain of repeated daily injections as well as the method of delivery, which virtually immobilizes the usually active young patients.

\section{Experimental Section}

\section{Preparation of IPN hydrogels (I1-I5)}

Acryl amide (AcAm), poly ethyleneimine (PEI) and bis acrylamide as crosslinker are dissolved in water then (1\%) sodium persulfate $\left(\mathrm{Na}_{2} \mathrm{~S}_{2} \mathrm{O}_{8}\right)$ is added as initiator and mixed well followed by addition of $(50 \mu \mathrm{l})$ tetramethylethylenediamine as accelerator at the initiation step with stirring for 10 minutes at $35^{\circ} \mathrm{C}$ to complete the polymerization reaction. Table 1 shows the quantities of reactants used in the preparation of IPN hydrogels $\left(I_{1}-I_{5}\right)$.

\section{Preparation of IPN hydrogels (E1-E5)}

Acryl amide (AcAm), Poly electrolyte and bis acrylamide as crosslinker are dissolved in water then (1\%) sodium persulfate $\left(\mathrm{Na}_{2} \mathrm{~S}_{2} \mathrm{O}_{8}\right)$ is added as initiator and mixed well followed by addition of $(50 \mu \mathrm{l})$ tetramethylethylenediamine as accelerator at the initiation step with stirring for 10 minutes at $35^{\circ} \mathrm{C}$ to complete the polymerization reaction. Table $\mathbf{2}$ shows the quantities of reactants used in the preparation of IPN hydrogels $\left(E_{1}-E_{5}\right)$.

\section{Preparation of copolymer hydrogels (AA1-AA8)}

Acryl amide (AcAm), Acrylic acid (AcAc) and bis acrylamide as crosslinker are dissolved in water then (1\%) sodium persulfate $\left(\mathrm{Na}_{2} \mathrm{~S}_{2} \mathrm{O}_{8}\right)$ is added as initiator and mixed well followed by addition of $(50 \mu \mathrm{l})$ tetra-methyl-ethylene-di-amine as accelerator at the initiation step with stirring for 10 minutes at $35^{\circ} \mathrm{C}$ to complete the polymerization reaction. Table 3 shows the quantities of reactants used in the preparation of Copolymer hydrogels (AA1-AA8).

\section{Synthesis of PLA-P127-PLA tri block copolymer}

Puloronic F-127 (12.5 g, 0.001 mole) and L-lactide (7.10 g , 0.05 mole) are dissolved into di chloro ethane. DBU $(100 \mu \mathrm{L})$ is added and the mixture is stirred for $24 \mathrm{~h}$ at $25^{\circ} \mathrm{C}$ under Argon atmosphere. The reaction is worked up by the slow addition the reactants to $500 \mathrm{ml}$ diethyl ether to precipitate the polymer which is then filtered on Buchner funnel and washed with diethyl ether and then dried in vacuum oven at $25^{\circ} \mathrm{C}$ for 24 hours [19]. $1 \mathrm{H}-\mathrm{NMR}$ and FTIR are measured and the yield of product is $70 \%$ yield. The reaction can be represented by the following reaction equation.

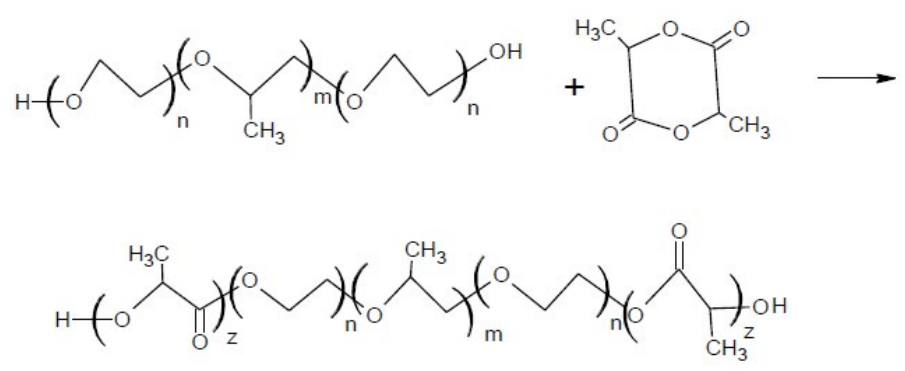

\section{Preparation of tetramethylol urea}

Tetramethylol urea is prepared adopting an experimental procedure which has been described in detail elsewhere [20].

Table 1: The composition used in the preparation of copolymer gels $\left(I_{1}-I_{5}\right)$.

\begin{tabular}{|c|c|c|c|}
\hline Sample No. & ACAm* $(\mathrm{g})$ & Bisacrylamide $(\mathrm{g})$ & PEI* $(\mathrm{g})$ \\
\hline $\mathrm{I}_{1}$ & 3 & 0.6 & 1 \\
\hline $\mathrm{I}_{2}$ & 3 & 0.6 & 2 \\
\hline $\mathrm{I}_{3}$ & 3 & 0.6 & 3 \\
\hline $\mathrm{I}_{4}$ & 1 & 0.2 & 3 \\
\hline $\mathrm{I}_{5}$ & 2 & 0.4 & 3 \\
\hline
\end{tabular}

${ }^{*} \mathrm{~A}_{\mathrm{c}} \mathrm{A}_{\mathrm{m}}$ : Acrylamide, **PEl: Poly Ethylene Imine. 


\section{Preparation of semi IPN loading with}

\section{desferroxamine}

$5 \mathrm{~g}$ Acrylamide, $1 \mathrm{~g}$ bis acryal amide,4 g PLA-P127-PLA tri block copolymer and $1 \mathrm{~g}$ Desferrioxamine methan sulphate (drug) are dissolved in $5 \mathrm{ml}$ distilled water and mixed well then sodium persulfate $\left(\mathrm{Na}_{2} \mathrm{~S}_{2} \mathrm{O}_{8}\right)$ and tetra methyl ethylene diamine are added with stirring at $35^{\circ} \mathrm{C}$ to complete the polymerisation reaction. The semi-IPN product is cut to several equal pieces and incubated at $35^{\circ} \mathrm{C}$. The pieces are then coated by solution of methylol urea in the presence of diluted sulfuric acid as catalyst by dip coating process.

\section{Characterization by scanning electron microscopy (SEM)}

Scanning electron microscopy is used to study the shape of prepared copolymers at xerogel, Figures $\mathbf{1}$ and $\mathbf{2}$ shows morphological characteristics for these hydrogels. The micrographs show that the polymers have a smooth surface as a base and Protruding from this smooth surface many of protrusions with different shapes and measurements. This is due to the presence of two types of repeating units in the prepared copolymers.

\section{Swelling studies}

The completely dried and accurately weighed poly (AcAc-AcAm) hydrogel is immersed in $50 \mathrm{~mL}$ of swelling medium at $25^{\circ} \mathrm{C}$ until the swelling equilibrium is attained (approximately for one day). The weight of the swollen gel $\left(\mathrm{W}_{\mathrm{e}}\right)$ is determined after removing the surface water gently with tissue paper. $\left(W_{d}\right)$ is the dry weight of the hydrogel [21].

Swelling $\%=\frac{W_{e}-W_{d}}{W_{e}} \times 100$

Figure 3 shows the micrographs of preparing triblock copolymer (PLA-127-PLA) and after removing water from the swollen

Table 2: The composition used in the preparation of IPN gels.

\begin{tabular}{|c|c|c|c|}
\hline Sample No. & AcAm (g) & Bisacrylamide (g) & Poly electrolyte (g) \\
\hline E1 & 3 & 0.6 & 1 \\
\hline E2 & 3 & 0.6 & 2 \\
\hline E3 & 3 & 0.6 & 3 \\
\hline E4 & 1 & 0.2 & 3 \\
\hline E5 & 2 & 0.4 & 3 \\
\hline
\end{tabular}

Table 3: The composition used in the preparation of Copolymer Hydrogels (AA1-AA8).

\begin{tabular}{|c|c|c|c|}
\hline Sample No. & AcAm $(\mathrm{g})$ & Bisacrylamide $(\mathrm{g})$ & AcAc* $(\mathrm{g})$ \\
\hline AA1 & 2 & 0.2 & 0 \\
\hline AA2 & 2 & 0.4 & 0 \\
\hline AA3 & 2 & 0.4 & 2 \\
\hline AA4 & 4 & 0.6 & 2 \\
\hline AA5 & 6 & 0.8 & 2 \\
\hline AA6 & 2 & 0.8 & 2 \\
\hline AA7 & 4 & 1.2 & 2 \\
\hline AA8 & 6 & 1.6 & 2 \\
\hline
\end{tabular}

*AcAc: Acrylic acid.

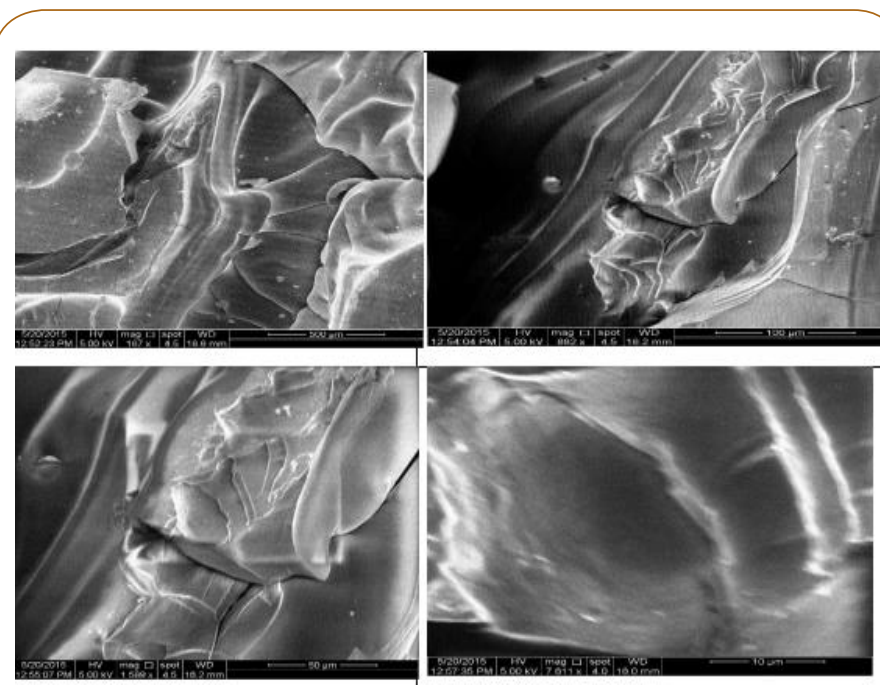

Figure 1 The SEM micrograph of the Copolymer AA8 with \%20 cross linker reagent, at different amplifications $(500,100,50,10) \mu \mathrm{m}$.
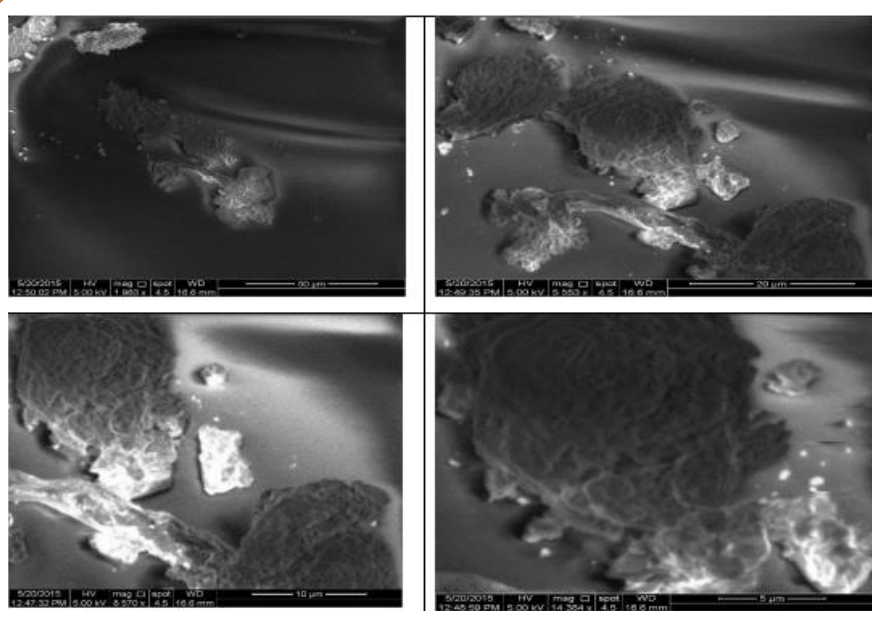

Figure 2 The SEM micrograph of the Copolymer AA6 with \%20 cross linker reagent, at different amplifications $(50,20,10,5) \mu \mathrm{m}$.
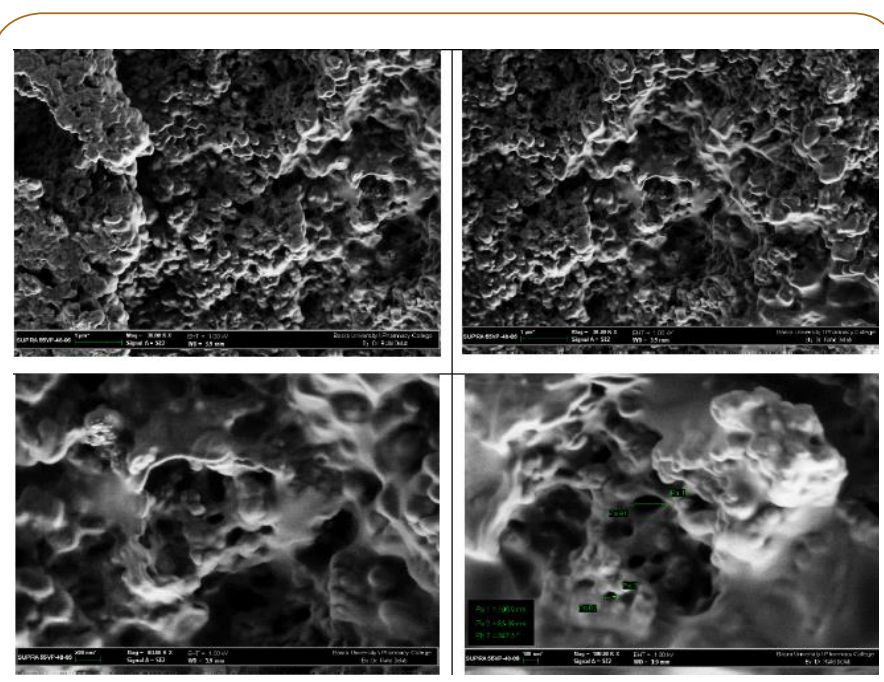

Figure 3 The FT-SEM micrograph of the triblock copolymer (PLAP127-PLA), at different amplifications (1 $\mu \mathrm{m}, 200 \mathrm{~nm}$, $100 \mathrm{~nm})$. 
hydrogels by Freeze Drying. The micrographs show presence of a large number of pores in different sizes On the other hand, Figure 4 shows presence of Nano structures which ranging from $35 \mathrm{~nm}$ to $95 \mathrm{~nm}$.

\section{Result and Discussion}

Figure 5 shows a ${ }^{1} \mathrm{H}$ NMR spectrum of (PLA-P127-PLA) in $\mathrm{CDCl}_{3}$. The peak at about $5.25 \mathrm{ppm}$ represented the $\left(-\mathrm{O}-\mathrm{CH}\left(\mathrm{CH}_{3}\right)-\mathrm{CO}-\right)$ of repeating unit of L-lactide segments (e), and at about $1.6 \mathrm{ppm}$ represent the methyl $\left(\mathrm{CH}_{3}\right)$ protons of lactide repeating units (b), $1.5 \mathrm{ppm}$ for methyl proton of propylene oxide repeating units (c) and at $1.45 \mathrm{ppm}$ for methyl proton of terminal lactide unit (a), the peaks between (3.5-3.7) ppm due to methylene protons ( $f, g$ and $\mathrm{h}$ ). The peak at about $4.3 \mathrm{ppm}$ for the two terminal protons $(\mathrm{CH})$ of L-lactide (d), the peak at $2.6 \mathrm{ppm}$ for hydroxyl groups at the end chains of polymers.

The swelling ratio of poly hydrogels in different swelling media including various $\mathrm{pH}$ (Simulated Gastro Fluid (SGF), Distilled Water and Simulated Intestinal Fluid (SIF) was studied. The Figures 6 and 7 show the swelling behaviour of copolymers (AA1, $A A 2$ and $A A 5, A A 8)$.

The prepared copolymer (AcAc-AcAm) hydrogels contain amine and carboxylate groups in their interpenetrated networks. Among these groups, the carboxylate group dissociation or swelling/ interaction is highly dependent on the $\mathrm{pH}$ of the medium [22]. We investigated the effect of $\mathrm{pH}$ on the swelling behavior of the Copolymer (AAc-AcAm) hydrogels by using buffer solutions with $\mathrm{pH}$ values of 1.2, 7 and 8.2. In the case of the Copolymer (AcAcco-AcAm) hydrogel, the amine group always shows the cationic charge in region acidic $(\mathrm{pH}=1.2)$ and the water content increased a little due to ionic repulsion.

In addition, since $\mathrm{Cl}^{-}$ions that can freely move exist in the solution, and the Donnan osmotic pressure based on the Donnan effect between free ion $\left(\mathrm{Cl}^{-}\right)$ion and fixed ion (cationic amine group) in AcAm occurs, the water content of hydrogel increased. Donnan effect is greatly dependent on ionic strength of the external solution. In the case of Copolymer (AcAc-AcAm) hydrogel, the carboxyl group of AcAc does not dissociate into the anion at $\mathrm{pH}=1.2$, but the amine group of AcAm shows the cationic charge at $\mathrm{pH}=1.2$. As a result, the hydrogel shows increase of water content due to repulsion by electrostatic interaction and swelling by the Donnan osmotic pressure as the hydrogel has the cationic charge.

In $\mathrm{pH}=7$, since the carboxyl group of AcAc and the amine group of AcAm have the electric charge, the water content of the hydrogel increases due to expansion by electrostatic interaction. In $\mathrm{pH}=8.2$, Copoly (AcAc-AcAm) hydrogel shows the anionic charge, because the amine group of AcAm does not show the cationic charge mostly and the carboxyl group of AcAc dissociate. Among these Functional groups, the carboxylate group dissociation or swelling/interaction is highly dependent on the $\mathrm{pH}$ of the medium [22]. Therefore, the water content of poly (AcAc-AcAm) hydrogel increases remarkably based on repulsion by electrostatic interaction between the carboxyl group and swelling by the Donnan osmotic pressure due to the Donnan effect between free ion (Nap) and fixed ion (carboxygroup of AAC).

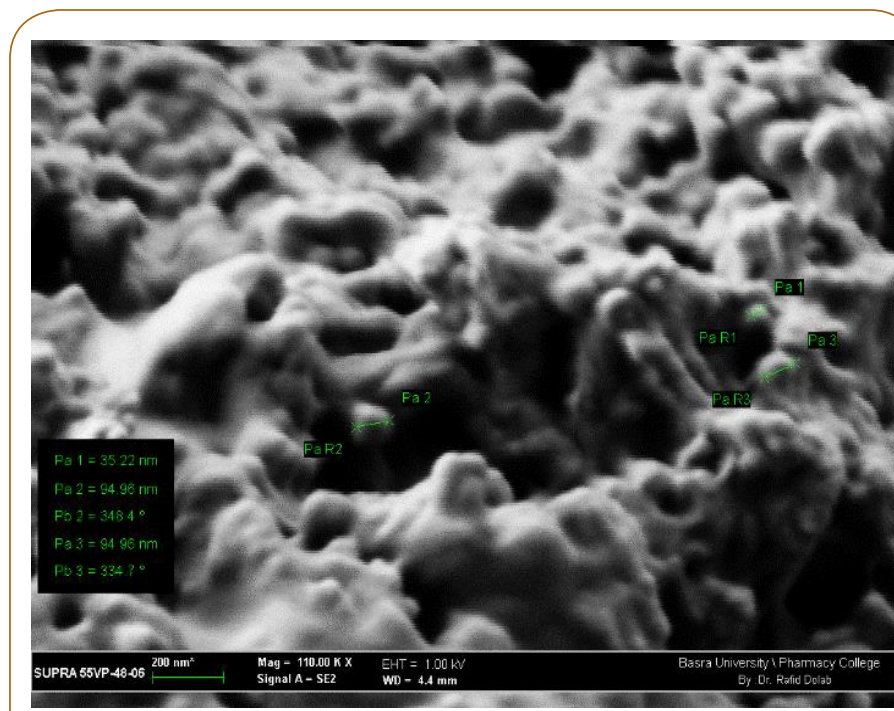

Figure 4 The FT-SEM micrograph of the triblock copolymer (PLAP127-PLA), at different amplifications $(200,100,200) \mathrm{nm}$.

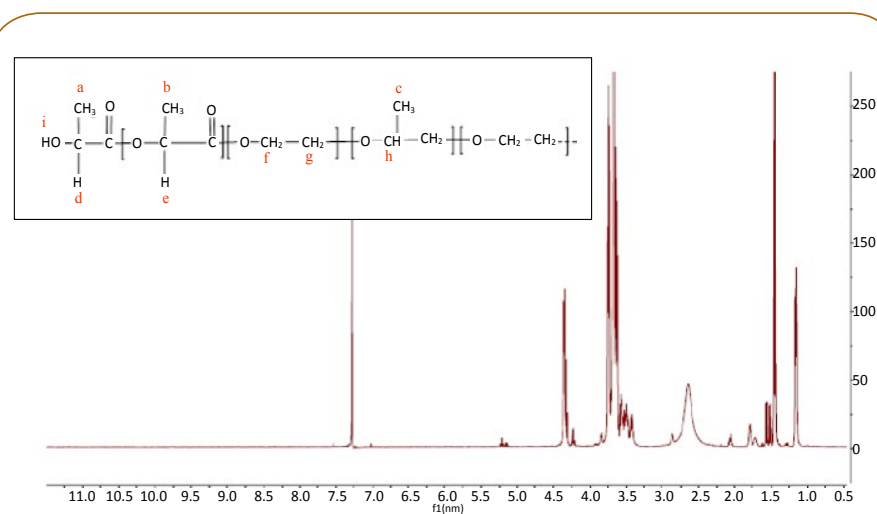

Figure 5 The1H-NMR spectrum of tri block copolymer PLA-PF127PLA.

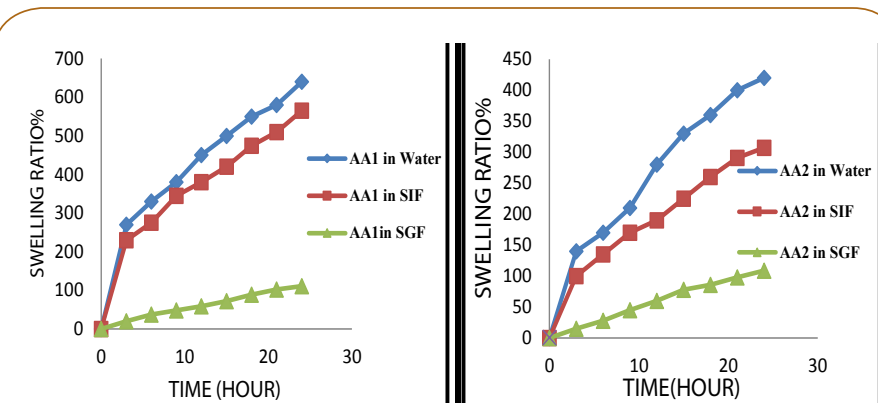

Figure 6 The swelling ratio of copolymer AA1and AA2 hydrogels at different $\mathrm{pH}$; (SGF, Water, SIF)

To determination the type of polymers that we have been chose to be iron ion chelated we prepared stander solution from ammonium iron sulphate (200-10) ppm with used 1,10 phenolphthalein as a selective detector for iron ions then used spectrophotometry in $505 \mathrm{~nm}$ to detected the best IPNs which sniped iron ions by beer's law equation. According to Table 2 shows the quantities of reactants used in the preparation of IPN hydrogels $\left(E_{1}-E_{5}\right)$, the results of \%Fe chelating values by time (minute) shown from Figures 8. 


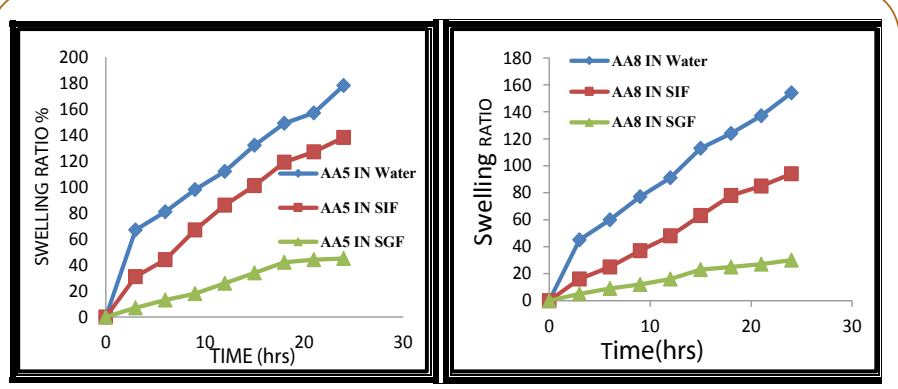

Figure 7 The swelling ratio of copolymer AA1and AA2 hydrogels at different $\mathrm{pH}$; (SGF, Water, SIF).
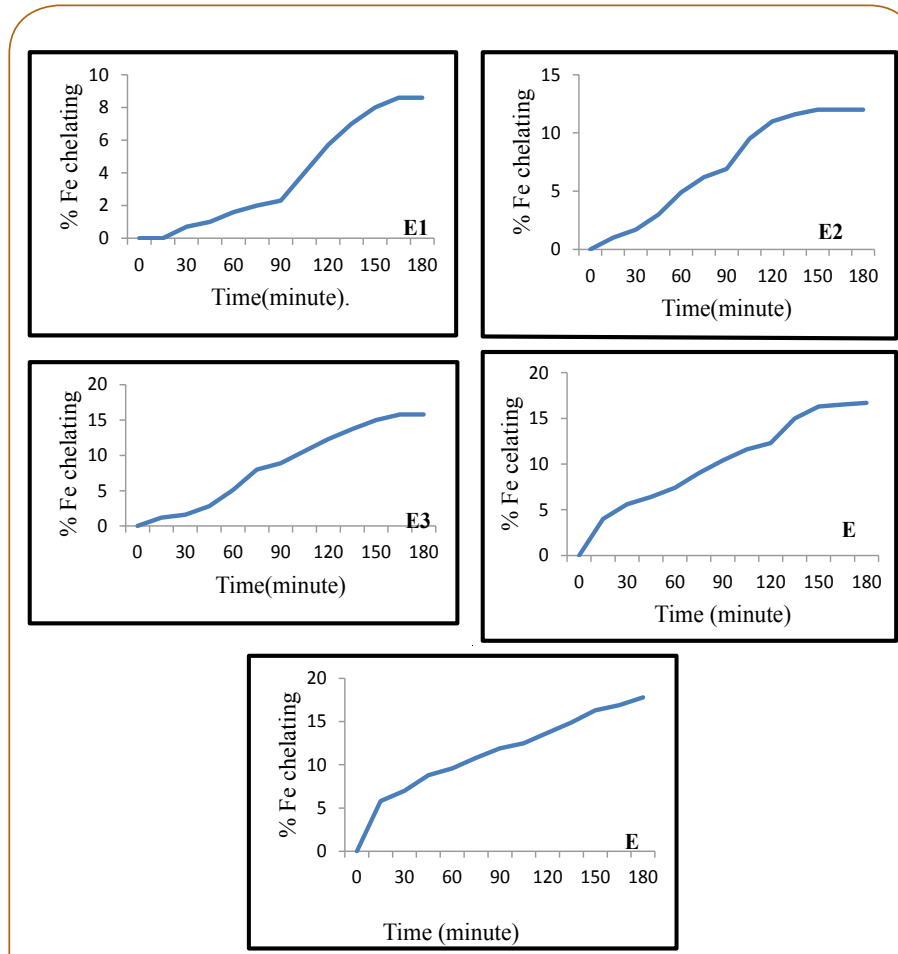

Figure 8 The results of \%Fe chelating of poly IPN [AAM: electrolyte (E1-E5)] hydrogels with time.

According to Table 3 shows the quantities of reactants used in the preparation of Copolymer hydrogels $\left(A_{3}-A_{8}\right)$, the results of \%Fe chelating values by time (minute) shown from Figure 9.

As the results of synthesis \& characterization of tri block copolymers (PLA-P127-PLA), that would be prepared semi IPN with poly acryl amid (AcAm) and loaded the gel with amount of Fe chelating drug (desferoxamine) according to the method in (2.6). The study included measuring the swelling capacity and the release of the drug in different PH solutions with \&without coating by tetramethylol urea.

The release study carried out at $\mathrm{pH} 1.2$ and 8.4 in a room temperature for $24 \mathrm{~h}$ and cumulative desferoxamine released was measured with suitable time interval and then determined spectrophotometry (UV-visible spectrometer) in a $1 \mathrm{~cm}$ cell at $203 \mathrm{~nm}$. Figures 10 and 11 showed the results of release studies.
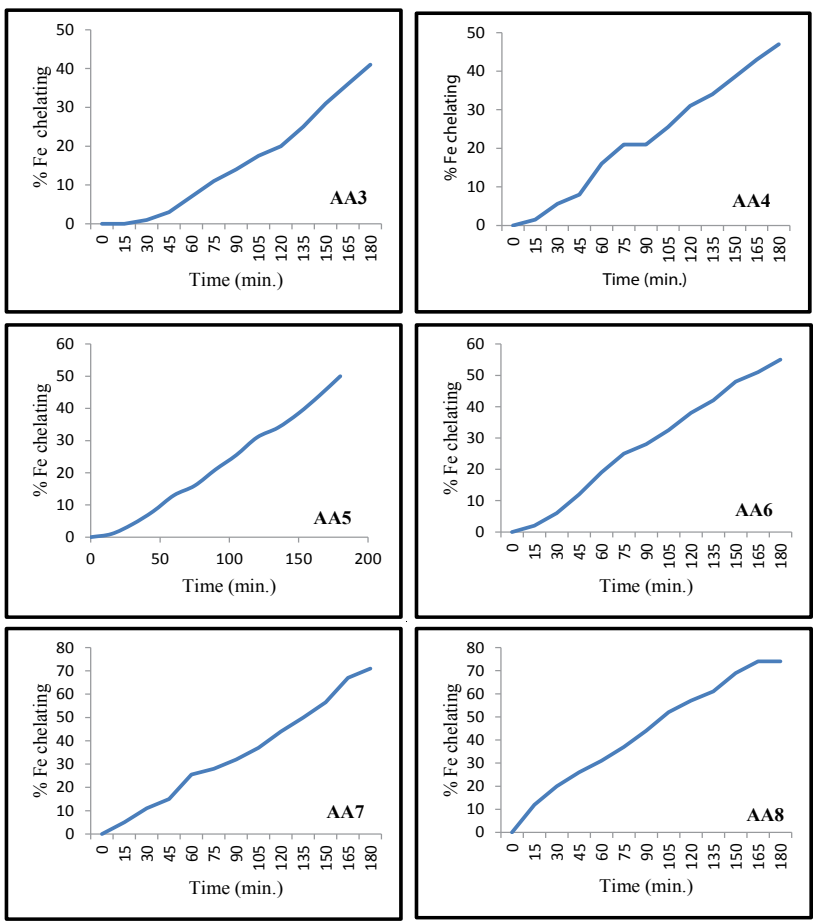

Figure 9 The results of chelating behavior of Copolymer [AcAAm (AA3-AA8)] hydrogels with time.

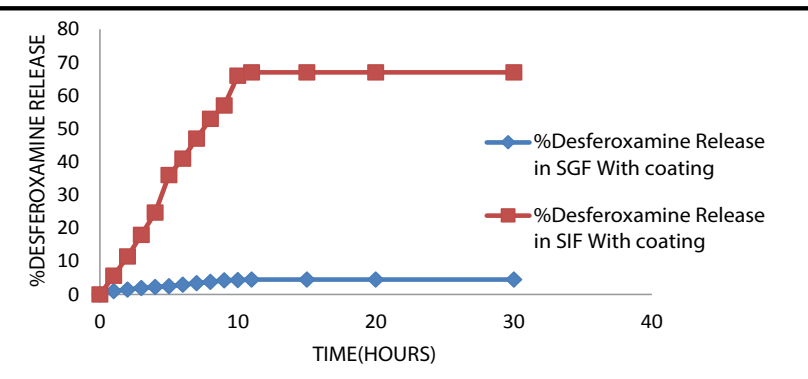

Figure 10 The \%Desferoxamine release loaded on Semi IPN PLA-P127-PLA with AAM) block copolymer with coating by Tetramethylol Urea agent in SIF and SGF during time (hours).

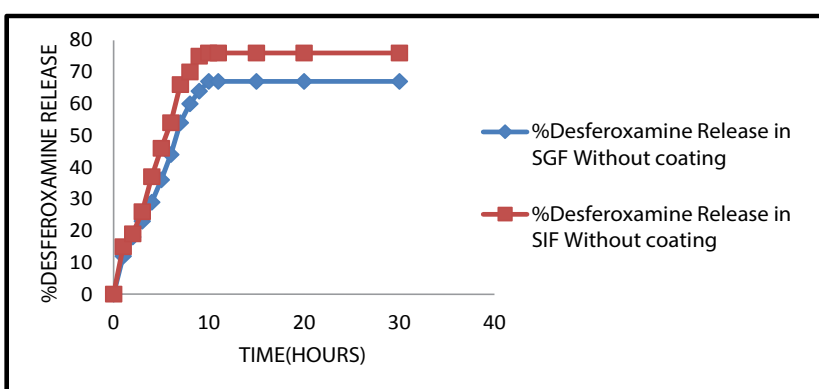

Figure 11 The \%Desferoxamine release loaded on Semi IPN (PLA-P127-PLA with AAM) block copolymer without coating by Tetramethylol Urea agent in SIF and SGF during time (hours). 


\section{References}

1 Baker JP, Blanch HW, Prausnitz JM (1995) Swelling properties of acrylamide-based ampholytic hydrogels: comparison of experiment with theory. Polymer 36: 1061-1069.

2 Huang G, Gao J, Hu Z, John JVS, Ponder BC, et al. (2004) Controlled drug release from hydrogel nanoparticle networks. Journal of Controlled Release 94: 303-311.

3 Mohan YM, Premkumar T, Joseph DK, Geckeler KE (2007) Stimuliresponsive poly ( $\mathrm{N}$-isopropylacrylamide-co-sodium acrylate) hydrogels: A swelling study in surfactant and polymer solutions. Reactive and Functional Polymers 67: 844-858.

4 Ogawa Y, Ogawa K, Wang B, Kokufuta E (2001) A biochemo-mechanical system consisting of polyampholyte gels with coimmobilized glucose oxidase and urease. Langmuir 17: 2670-2674.

5 Takeoka Y, Berker AN, Du R, Enoki T, Grosberg A, et al. (1999) First order phase transition and evidence for frustrations in polyampholytic gels. Physical Review Letters 82: 4863.

6 Mafé S, Manzanares JA, English AE, Tanaka T (1997) Multiple phases in ionic copolymer gels. Physical Review Letters 79: 3086.

7 Bergeron RJ, Wiegand J, Weimar WR, McManis JS, Smith RE, et al. (2003) Iron chelation promoted by desazadesferrithiocin analogs: an enantioselective barrier. Chirality 15: 593-599.

8 Barnham KJ, Masters CL, Bush Al (2004) Neurodegenerative diseases and oxidative stress. Nature Reviews Drug Discovery 3: 205-214.

9 Lieu PT, Heiskala M, Peterson PA, Yang Y (2001) The roles of iron in health and disease. Molecular Aspects of Medicine 22: 1-87.

10 Shinar E, Rachmilewitz EA (1990) Oxidative denaturation of red blood cells in thalassemia. In Seminars in hematology 27: 70-82.

11 Schrier SL, Centis F, Verneris M, Ma L, Angelucci E (2003) The role of oxidant injury in the pathophysiology of human thalassemias. Redox Report 8: 241-245.

12 Wong C, Richardson DR (2003) $\beta$-Thalassaemia: emergence of new and improved iron chelators for treatment. The International Journal of Biochemistry \& Cell Biology 35: 1144-1149.

13 Tam TF, Leung-Toung R, Li W, Wang Y, Karimian K, et al. (2003) Iron chelator research: past, present, and future. Current Medicinal Chemistry 10: 983-995.

14 Liu ZD, Hider RC (2002) Design of iron chelators with therapeutic application. Coordination Chemistry Reviews 232: 151-171.

15 Chiani M, Akbarzadeh A, Farhangi A, Mazinani M, Saffari Z, et al. (2010) Optimization of culture medium to increase the production of desferrioxamine B (desferal) in Streptomyces pilosus. Pakistan Journal of Biological Sciences 13: 546.

16 Schupp T, Toupet C, Divers M (1988) Cloning and expression of two genes of Streptomyces pilosus involved in the biosynthesis of the siderophore desferrioxamine B. Gene 64: 179-188.

17 Kontoghiorghes GJ, Pattichi K, Hadjigavriel M, Kolnagou A (2000) Transfusional iron overload and chelation therapy with deferoxamine and deferiprone (L1). Transfusion Science 23: 211-223.

18 Marcus RE, Davies S, Bantock HM, Underwood SR, Walton S, et al. (1984) Desferrioxamine to improve cardiac function in ironoverloaded patients with thalassaemia major. The Lancet 323: 392-393.

19 Wang D, Fredericks PM, Haddad A, Hill DJ, Rasoul F, et al. (2011) Hydrolytic degradation of POSS-PEG-lactide hybrid hydrogels. Polymer Degradation and Stability 96: 123-130.

20 Adam GA, Jabar FJ, Al-Kass SS (1994) Iraqi patent 2543.

21 Caykara T, Inam R (2003) Determination of the competitive adsorption of heavy metal ions on poly (n-vinyl-2-pyrrolidone/ acrylic acid) hydrogels by differential pulse polarography. Journal of Applied Polymer Science 89: 2013-2018.

22 Kakinoki S, Kaetsu I, Nakayama M, Sutani K, Uchida K, et al. (2003) Temperature and $\mathrm{pH}$ responsiveness of poly-(DMAA-co-unsaturated carboxylic acid) hydrogels synthesized by UV-irradiation. Radiation Physics and Chemistry 67: 685-693. 